\title{
Priorities for a new government: keeping the Medicare promise, thinking beyond services and getting governance right
}

\section{Health policy priorities should include more than just one-term quick fixes}

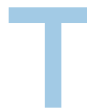

he present Australian Government was elected with almost no health policy. It presented a small target and basically said "trust us, we'll be like them" (the outgoing government). However, now that it is governing, it needs to set policies and priorities. Although the opinion polls suggest that re-election for a second term is not assured, good governments should start thinking of second-term issues on Day 1 - the next election is fewer than 1000 days away, and significant policies take more than 3 years to address.

There are three broad areas that warrant priority attention (Box).

A critical electoral priority for the new government is keeping the Medicare promise. The Medibank promise of 40 years ago, reaffirmed with Medicare 30 years ago this year, was that financial barriers to care would be removed, and people would be able to access public hospital care, free at point of service, when they needed it. Both commitments are under challenge, with $14 \%$ of the population reporting deferring or not seeking medical care in the past year because of cost, ${ }^{1}$ and governmentendorsed waiting time targets not being achieved. Although these issues are longstanding, the government needs to set in train processes to tackle more fundamental (and longer-term) issues, such as improving the interface between primary care and hospital care and improving mental health care.

Given the fiscal pressure the government is under, it will only be able to keep the Medicare promise if the health sector is vigilant about increasing efficiency and eliminating waste. Health costs are predicted to consume

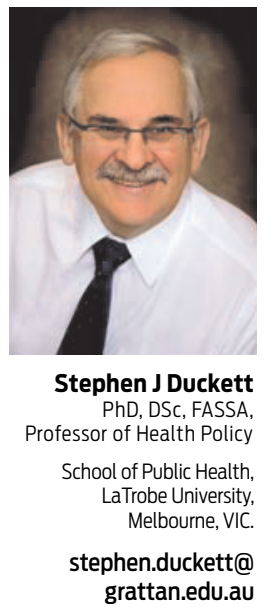

doi: $10.5694 / \mathrm{mja} 3.00224$ include addressing social determinants of health (and
responding to the all-party Senate committee report ${ }^{6}$ ) and
Indigenous health. Indigenous health.

There are also foundational issues to be addressed. The National Health and Hospitals Reform Commission recognised the importance of getting system governance right - to ensure there are functioning national agencies, not just federal-state forums paralysed by processes. ${ }^{7}$ The previous government's response was an alphabet soup of new agencies, many of which are still finding their feet. Although some rationalisation of these is feasible, ensuring good system governance for truly national issues remains a priority. Other structural issues include improving access to data to facilitate research and evaluation, ${ }^{8}$ getting better value from the research dollar, ${ }^{9}$

\footnotetext{
Health policy issues for the Abbott government

Issue

Keeping the

Medicare promise

First-term agenda

- Address out-of-pocket expenses

- Work with states on hospital access

- Cut waste

- Reform the workforce

Beyond services

- Develop the evidence

Tackle Indigenous health

Develop supportive communities

Address the social determinants of health

Managing the system

- Clarify the structure (both national agencies and primary care system roles, including the future of Medicare Locals)

- Improve access to data for accountability and evaluation

- Revitalise research

- Facilitate a "continuous learning health system"

(Potential) Second-term agenda

- Improve the interface between primary and secondary care

- Reform mental health

- Implement evidence-based prevention and remediation strategies nationally

- Build architecture for data on health outcomes
} 
and using existing routine data to drive improvement in care in hospitals. ${ }^{10}$

Health care is replete with "wicked problems" — those that involve incomplete or contradictory knowledge and opinions, affect a lot of people and cost a lot to fix. ${ }^{11}$ Typically, solving them may create other problems, or at least impact on other, interconnected issues. This means that there are rarely easy answers and quick fixes. Good health policy thus stretches over multiple parliamentary terms, and should involve an acknowledgement that there is a lack of knowledge about what needs to be done. Policy experimentation may be required.

Acknowledging such difficulties and uncertainties in developing good health policy is a hard thing for leaders to do in the parliamentary bear pit. Although bipartisan reform may be too much to hope for, we can at least hope for recognition that a development path for policy is required.

Competing interests: No relevant disclosures.

Provenance: Commissioned; not externally peer reviewed.

1 Schoen C, Osborn R, Squires D, Doty MM. Access, affordability, and insurance complexity are often worse in the United States compared to ten other countries. Health Aff (Millwood) 2013; 32: 2205-2215.

2 Goss J. Projection of Australian health care expenditure by disease, 2003 to 2033. Canberra: AlHW, 2008. (AlHW Cat. No. HWE 43; Health and Welfare Expenditure Series No. 36.) http://www.aihw.gov.au/publication-detail/?id= 6442468187 (accessed Jan 2014).

\section{8 \\ Acknowledging such difficulties and}

uncertainties in

developing

good health

policy is a hard

thing for leaders

to do in the

parliamentary

bear pit

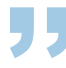

3 Daley J, McGannon C, Savage J. Budget pressures on Australian governments. Melbourne: Grattan Institute, 2013. http://grattan.edu.au/static/files/assets/ ff6f7fe2/187_budget_pressures_report.pdf (accessed Jan 2014).

4 Duckett S, Breadon P, Ginnivan L, Venkataraman P. Australia's bad drug deal: high pharmaceutical prices. Melbourne: Grattan Institute, 2013. http:// grattan.edu.au/static/files/assets/5a6efeca/Australias_Bad_Drug_Deal_ FINAL.pdf (accessed Jan 2014).

5 Duckett S, Breadon P, Ginnivan L, Nolan J. Poor pricing progress: price disclosure isn't the answer to high drug prices. Melbourne: Grattan Institute, 2013. http:// grattan.edu.au/static/files/assets/003dbl4b/803-Poor-Pricing-Progress.pdf (accessed Jan 2014).

6 Australian Senate Community Affairs References Committee. Australia's domestic response to the World Health Organization's Commission on Social Determinants of Health report "Closing the gap within a generation". Canberra: Commonwealth of Australia, 2013.

7 National Health and Hospitals Reform Commission. A healthier future for all Australians. Final report. Canberra: Commonwealth of Australia, 2009. http:// www.yourhealth.gov.au/internet/yourhealth/publishing.nsf/content/nhhrcreport-toc\#.Ut9yW_s7bGg (accessed Jan 2014).

8 Academy of the Social Sciences in Australia. Facilitating access to routine data for research benefiting the Australian people. Canberra: ASSA, 2013. http:// cms.assa.edu.au/.pdf/submissions/assa_submission_health_data 2013(2).pdf (accessed Jan 2014).

9 Australian Government Department of Health and Ageing. Strategic review of health and medical research: better health through research. Final report. Canberra: Commonwealth of Australia, 2013. http://

www.mckeonreview.org.au/downloads/Strategic_Review_of_Health_and_ Medical_Research_Feb_2013-Final_Report.pdf (accessed Jan 2014).

10 Etheredge LM. A rapid-learning health system. Health Aff (Millwood) 2007; 26: w107-w118.

11 Rittel HWJ, Webber MM. Dilemmas in a general theory of planning. Policy Sciences 1973; 4: 155-169. 